COMMENT

Received 25 Jun 2015 | Accepted 27 Jul 2015 | Published 1 Sep $2015 \quad$ DOl: 10.1057/palcomms.2015.21

OPEN

\title{
Interdisciplinarity and anxiety
}

Raphael Lyne ${ }^{1}$

ABSTRACT At the level of institutional strategy, interdisciplinary research looks like a positive and productive exchange. At the personal level, where it is enmeshed with career progress, disciplinary anxieties and tensions at the interface between sometimes incommensurate kinds of thinking, there can be frictions and difficulties. These, however, are part of what makes such research so valuable, in that they enable individuals and groups within subjects on both sides to uncover those things that need to be better understood. This article forms part of an ongoing thematic collection dedicated to interdisciplinary research.

\footnotetext{
${ }^{1}$ Fellow of Murray Edwards College, University of Cambridge, Cambridge, UK (e-mail: rtr1100@cam.ac.uk)
} 


\section{Introduction}

nterdisciplinarity often reflects scholars' aspirations to find and demonstrate the progressive vitality of their fields. However, it may also reflect some uncertainty in a subject, even an anxious sense of inadequacy, from which people reach out to find other sources of substance and validation. In trying to characterize both aspiration and anxiety in this essay, I will offer some general and some anecdotal reflections, and I am doing the latter with a particular sense of purpose. Jacob's (2015) inaugural contribution to this series took a strategic overview of interdisciplinarity and what it has to offer. I want to complement this with a contribution that testifies less at the level of strategy, and more at the level of personal, contingent tactics, exposed to small- and large-scale pressures, and especially one that recognizes the tensions and discontinuities within and between disciplines.

At the 2015 Renaissance Society of America conference in Berlin a panel celebrated the twenty-fifth anniversary of the publication of Jardine and Grafton's (1990) seminal essay "Studied for Action: How Gabriel Harvey Read his Livy". At the outset of my research career, as a Master's student in English Renaissance Literature, this article was one of the things I read that showed me how postgraduate study would be different from undergraduate study. It made me realize that being interdisciplinary, putting literary criticism into conversation with (in this case) intellectual history and book history, was something I could and perhaps ought to be doing. I mainly wanted to read texts, think about their relations to one another, what they did to and for their first readers, and what they do to and for readers now, which seemed to me to be the basic business of my subject. Nevertheless a few years later I followed my friends down to Queen Mary where Jardine and others were hosting a conference called "Eloquence and Economics". I saw links made with economic, social and material history, and a broad international scope (Mediterranean politics and beyond; cartography and trade). It was an excellent event, but it wasn't much related to my work. Nowadays I think there are more conferences to choose from, and I might find something more immediately germane; but of course there is still great value in finding out where the frontiers of a subject are being tested.

The conference and the Harvey-Livy paper were one small part of a general turn towards interdisciplinarity in the English departments I know. Even as I carried on doing literary criticism, and was fortunate to find readers and students and colleagues and publishers engaged in similar pursuits, I knew that the term "interdisciplinary" had become an inherently positive one, and denoted a kind of work that could generate opportunities for grants and jobs. In 2004 it was time for me to plan a new project, and I had an open mind; in my case the openness of mind was surely helped by the fact I had a secure position. I was motivated by a specific intellectual challenge and also by a feeling of enervation in my research. I wanted to find a different way of writing about the issues in literary criticism that had already occupied me for a decade, namely, imitation and intertextuality, how poets base their work on other poems, how plays re-present material from their sources and many associated nuances. Early attempts to think this through made one key metaphor, memory, seem like a way of both holding together the diverse elements of the question, and generating finer distinctions. In my wide reading on memory one field unexpectedly came to the fore as a source of congenial insights, suggestive categories and energetic differences: cognitive science. At the time other literary scholars were beginning to embrace comparable connections (Spolsky, 2001; Crane, 2003, were particular inspirations; Richardson, 2004, surveyed the field), and I found myself happily in the field of "Cognitive Literary Studies".

Subsequently it has grown and to some extent flourished: There are some landmark anthologies that gather instructive essays together (Zunshine, 2010, 2015). There has been excellent work on Shakespeare that has been particularly useful to me (McConachie, 2008; Cook, 2010; Tribble, 2011). My book on memory and imitation is now in press, after a longish battle, out of which other publications have emerged (Lyne, 2011, 2012, 2013, 2014a, b). When fellow-travellers gather we have plenty to discuss, but here I want to focus on inhibiting factors more than enabling ones. Rather than emphasizing the stimulating and energizing possibilities I find in this work, I want to consider the inequalities of interdisciplinarity -because the thing is, I have had the good fortune to speak with numerous fascinating, thoughtful scientists who are sympathetic to the humanities and see ways in which our interests and questions converge. Structurally, however, our disciplines are disposed very differently towards the benefits of such conversations. Early on, a senior colleague introduced me to a third party as someone engaged in important interdisciplinary work. As far as I knew, she did not think much of what I was asking or concluding, but "the i-word" was a badge of honour; whereas, not many careers in the cognitive sciences have been based on opening the discipline in the direction of literary scholarship. The discipline already has a wide span, taking in imaginatively configured behavioural experiments and the brute power of big machines (MRI; MEG). It might look further into the biological and social sciences at times, and it might also intersect productively with philosophy around questions of mind; but finding out what Shakespeare and his characters and his critics think about thinking is less likely.

As it happens I think this should be done more, which is why I write an exploratory blog with a title-"What Literature Knows About Your Brain"-designed as a gentle provocation (http:// www.english.cam.ac.uk/research/cogblog). Some collaborative research projects that value the insights from both sides have flourished, or are continuing to do so: I am thinking here of the ongoing interdisciplinary work of Sutton and Tribble (as in Tribble and Sutton, 2011), the Balzan Foundation Prize-funded "Literature as an Object of Knowledge", led by Terence Cave (https://www.sjc.ox.ac.uk/3179/The-Project.html), and the "History of Distributed Cognition" project ongoing in Edinburgh (http://www.hdc.ed.ac.uk/). I have also followed with interest the dialogue between Wojciehowski and Gallese $(2010,2011)$, where I think there is a very productive and accommodating two-way exchange between a literary scholar and a neuroscience pioneer (Gallese is associated with mirror neurons which have been both influential and controversial in literary studies). Nevertheless, while my conviction that poems and plays and novels are sources of psychological insight is commonplace in some ways, trying to make that insight impinge on psychology itself sometimes feels like a quixotic task.

In the case of English, the interdisciplinary turn can represent the liveliness of a discipline reaching out and accommodating new ideas, but it can also seem like a sign of anxiety. Leavis wrote as if his subject encompassed others (Leavis, 1975; see Moran, 2002: 180-181; McDonald, 2007, for reflections on the changing profile of criticism), and was thus interdisciplinary by nature. Now it sometimes seems like the turn towards theology or law, or whatever can arise from an effort to overcome a kind of inadequacy. Whether this is inadequacy in that truly understanding Paradise Lost requires more than just careful close analysis, or inadequacy in that practising literary criticism without engaging in another discipline looks like a niche activity, or something else, varies from person to person. I can say that for me it's a question of vitality; I think literature and criticism have enormous amounts to contribute to debates about the mind; but I 
suppose I may be part of an institutionalized self-abasement to a greater extent than I'd like to admit.

Although interdisciplinarity as a research method seems easy to explain to people in my field, cognitive science as a particular path, and as a subject in itself, has its detractors. Some of my colleagues view, for example, MRI experiments as a blunt and naïve instrument with which to understand the mind in any of its functions, let alone in anything as complex as the effects of literary works (not that I have ever tried to do anything myself with scans of reading brains). They point at what looks like looseness in dealing with philosophical categories and terms. On first hearing of my new direction, one cheerfully recommended The Philosophical Foundations of Neuroscience (Bennett and Hacker, 2003), then recently published, as a comprehensive demolition of the whole discipline. In the end I decided it was not exactly that, but its assertions about the problematic use of language in cognitive science exert a considerable pull on the sympathies of a literary person.

Other colleagues listen to their physical scientist friends and read "bad science" exposés, and are quick to conclude that psychology in general has problems with statistics, evidence, conclusions and more. They know about debates over replication (what happens when an attempt to repeat a respected experiment doesn't produce the same result), and note that some parts of the discipline are turning against their own methods. We understand that in English departments; we have done it too. I certainly don't think it would be fruitful to propose an alliance between two disciplines based on the feeling that they might be a bit worried and beleaguered because of the softness of their evidence. As well as being impolitic in all sorts of ways, this would misrepresent my trust in the resourcefulness and thoughtfulness of both sides of the interdisciplinary equation.

There are simpler problems. I have become used to using the word "cognition" in the sense most psychologists seem to use it, to refer to everything that the mind does. So it could be sensorimotor, rational, emotional, social, depending on the context. Some of my colleagues, on the other hand, with good reason, and in the light of established practice in the humanities, use it to mean reasoning as opposed to feeling-so emotions, and motor responses, for example, are not included. This is only a minor inconvenience, but it is also an itch that won't quite go away.

I think the situation I am describing is particular to my own interdisciplinary niche, but versions of it exist in many others. This kind of work isn't just about expanding horizons, incorporating new heuristic methods, making fruitful contacts. It's also about exposing the tensions within one's own discipline, facing the individual scholar's anxious relationship with those tensions, realizing the limitations of competence, encountering the foibles of another discipline and working out how to address mutual inadequacies (with tact and generosity of spirit; with a bit of partisan resistance). The narrative involved is less upbeat, mostly because it is carried out on the individual rather than the institutional scale, but also because self-awareness can be challenging. I realize I am not singing a siren song here, even though confidence and passion underlie my assertions that no discipline can understand the mind on its own, and that a combination of approaches is most likely to fathom its possibilities. (In that respect I am no less optimistic than Bondebjerg, 2015, in his essay in this very series.) In the end, though, I think the versions of anxiety I have been describing make interdisciplinarity more rather than less valuable to the academic environment and to one's own career.

\section{References}

Bennett M R and Hacker P M S (2003) Philosophical Foundations of Neuroscience. Blackwell: Oxford.

Bondebjerg I (2015) The embodied mind: When biology meets culture and society. Palgrave Communications; $1,15015$.

Cook A (2010) Shakespearean Neuroplay: Reinvigorating the Study of Dramatic Texts and Performance Through Cognitive Science. Palgrave Macmillan: Basingstoke.

Crane M T (2003) Shakespeare's Brain: Reading with Cognitive Theory. Princeton University Press: Princeton, NJ.

Jacob W J (2015) Interdisciplinary trends in higher education. Palgrave Communications; $1,15001$.

Jardine L and Grafton A (1990) "Studied for action": How Gabriel Harvey read His Livy. Past and Present; 129 (1), 30-78.

Leavis F R (1975) The Living Principle: "English" as a Discipline of Thought. Chatto and Windus: London.

Lyne R (2011) Shakespeare, Rhetoric and Cognition. Cambridge University Press: Cambridge.

Lyne R (2012) Recognition in Cymbeline In: Loughnane R and Power A (eds) Late Shakespeare 1608-1613. Cambridge University Press: Cambridge, pp 56-70.

Lyne R (2013) The Shakespearean grasp. Cambridge Quarterly; 42 (1), 38-61.

Lyne R (2014a) Shakespeare, perception and theory of mind. Paragraph; 37(1), 79-95.

Lyne R (2014b) Thinking in Stanzas: Venus and Adonis and The Rape of Lucrece In: Scott-Baumann E and Burton B (eds) The Work of Form: Poetics and Materiality in Early Modern Culture. Cambridge University Press: Cambridge, pp 88-103.

McConachie B (2008) Engaging Audiences: A Cognitive Approach to Spectating in the Theatre. Palgrave Macmillan: Basingstoke, UK.

McDonald R (2007) The Death of the Critic. Continuum: London.

Moran J (2002) Interdisciplinarity. Routledge: London and New York.

Richardson A (2004) Studies of literature and cognition: A field map In: Richardson A and Spolsky E (eds) The Work of Fiction: Cognition, Culture, and Complexity. Ashgate: Aldershot, UK, pp 1-29.

Spolsky E (2001) Satisfying Skepticism: Embodied Knowledge in the Early Modern World. Ashgate: Aldershot, UK.

Tribble E (2011) Cognition in the Globe: Attention and Memory in Shakespeare's Theatre. Palgrave Macmillan: Basingstoke, UK.

Tribble E and Sutton J (2011) Cognitive ecology as a framework for Shakespearean studies. Shakespeare Studies; 39 (1), 94-103.

Wojciehowski H and Gallese V (2010) "The Mirror Neuron Mechanism and Literary Studies: An Interview with Vittorio Gallese”. California Italian Studies 1: http://escholarship.org/uc/item/56f8v9bv.

Wojciehowski H and Gallese V (2011) "How Stories Make Us Feel: Toward an Embodied Narratology”. California Italian Studies 2: http://escholarship.org/uc/ item/3jg726c2.

Zunshine L ed. (2010) Introduction to Cognitive Cultural Studies. Johns Hopkins University Press: Baltimore, MD.

Zunshine L ed. (2015) Oxford Handbook of Cognitive Literary Studies. Oxford University Press: Oxford.

\section{Additional Information}

Competing interests: The author declares no competing financial interests.

Reprints and permission information is available at http://www.palgrave-journals.com/ pal/authors/rights_and_permissions.html

How to cite this article: Lyne R (2015) Interdisciplinarity and Anxiety. Palgrave Communications. 1:15021 doi: 10.1057/palcomms.2015.21.

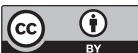

This work is licensed under a Creative Commons Attribution 3.0 International License. The images or other third party material in this article are included in the article's Creative Commons license, unless indicated otherwise in the credit line; if the material is not included under the Creative Commons license, users will need to obtain permission from the license holder to reproduce the material. To view a copy of this license, visit http://creativecommons.org/licenses/by/3.0/ 